ARTIGO

\title{
DO GÊNERO À “IDEOLOGIA DE GÊNERO” NO CAMPO DAS POLÍTICAS EDUCACIONAIS: APONTAMENTOS TEÓRICOS, HISTÓRICOS E POLÍTICOS
}

\author{
FROM GENDER TO “GENDER IDEOLOGY” IN THE FIELD OF EDUCATIONAL \\ POLICIES: THEORETICAL, HISTORICAL AND POLITICAL NOTES
}

\section{DEL GÉNERO A LA "IDEOLOGÍA DE GÉNERO" EN EL ÁMBITO DE LAS POLÍTICAS EDUCATIVAS: NOTAS TEÓRICAS, HISTÓRICAS Y POLÍTICAS}

\author{
Neiva Furlin \\ Universidade do Oeste de Santa Catariana - Brasil
}

\begin{abstract}
Resumo: A partir do início deste século, criaram-se mecanismos estatais para incluir gênero e sexualidades nas políticas educacionais, respondendo exigências de organismos internacionais. Ao lado disso, levantaram-se vozes conservadoras que produziram a narrativa nomeada "ideologia de gênero", visando desqualificar estudos acadêmicos e conter os avanços dos direitos voltados à igualdade de gênero e o reconhecimento das diversidades sexuais. Este artigo, teórico-reflexivo, analisa como o gênero foi incorporado nas políticas educacionais, em vista de processos de transformação socioculturais e como se tornou um elemento de disputa política, por parte dos setores conservadores, que transformou o gênero em inimigo a ser combatido. Trata-se de um projeto que oculta interesses específicos e que coloca em jogo um modelo de sociedade e de educação democrática, pautada na igualdade de direitos e na convivência plural.
\end{abstract}

Palavras-chave: Educação democrática; Conceito de gênero; "Ideologia de gênero".

\begin{abstract}
From the beginning of this century, state mechanisms were created to include gender and sexuality in educational policies, responding to the demands from international organizations. Alongside this, conservative voices were raised that produced the narrative named "gender ideology," aiming to disqualify academic studies and contain advances in rights aimed at gender equality and the recognition of sexual diversity. This theoretical-reflective article analyzes how gender has been incorporated into educational policies, in view of socio-cultural transformation processes and how it has become an element of political dispute on the part of conservative sectors, turning gender into an enemy to be fought. It is a project that hides specific interests and puts at stake a model of society and democratic education based on equal rights and plural coexistence.
\end{abstract}

Keywords: Democratic education; Gender concept; "Gender ideology".

Resumen: Desde el principio de este siglo, se han creado mecanismos estatales para incluir el género y la sexualidad en las políticas educativas, respondiendo a las demandas de las organizaciones internacionales. Junto a esto, se han alzado voces conservadoras produciendo la narrativa llamada "ideo- 
logía de género", con el objetivo de descalificar los estudios académicos y contener avances en los derechos destinados a la igualdad de género y el reconocimiento de la diversidad sexual. Este artículo teórico-reflexivo analiza cómo se ha incorporado el género en las políticas educativas, en vista de los procesos de transformación sociocultural y cómo se ha convertido en un elemento de disputa política por parte de los sectores conservadores, lo que ha convertido al género en un enemigo a combatir. Este es un proyecto que esconde intereses específicos y pone en juego un modelo de sociedad y educación democrática, basado en la igualdad de derechos y la convivencia plural.

Palabras clave: Educación democrática; Concepto de género; "Ideología de género".

\section{Questões introdutórias: gênero como categoria analítica e política}

O termo gênero se tornou popular a partir da década de 1990, mas já era utilizado pela teoria social desde a década de 1970, como forma de compreender os comportamentos, as relações e as hierarquias sociais que se estabeleciam entre homens e mulheres. Trata-se de um conceito analítico que surgiu do debate crítico do movimento feminista norte-americano na sua articulação com estudos acadêmicos, no período conhecido como "segunda onda" do feminismo, quando além das preocupações sociais e políticas, as construções teóricas epistemológicas ganharam importância (LOURO, 1999).

O conceito de gênero se constituiu uma ferramenta teórica para problematizar as desigualdades entre homens e mulheres e evidenciar que elas não resultavam da diferença biológica, mas de uma construção sócio-histórica legitimada pelos padrões normativos da sociedade patriarcal. Apesar de ter sido um conceito sistematizado e construído teoricamente no interior do debate feminista contemporâneo, sua origem tem sido atribuída à afirmação de Simone de Beauvoir (1949), de que "não se nasce mulher, se torna mulher”, por meio da qual ela problematizava as relações entre sexo biológico e construção da categoria social de mulher.

Partindo desse pressuposto, pensadoras contemporâneas elaboraram a categoria analítica de gênero, apontando o caráter sociocultural das diferenças que, até então, eram compreendidas como inerentes à natureza do sexo biológico. Com o argumento da construção social de gênero, rejeita-se a perspectiva da determinação biológica, que justificava as desigualdades sociais entre homens e mulheres e apresentam-se as primeiras explicações contemporâneas para o gênero. A concepção de "sistema de sexo/gênero" da antropóloga Gayle Rubin (1993), que nomeava os aspectos políticos, econômicos e sociais do sistema "sexo/gênero" foi um marco importante para os estudos de gênero.

Jane Flax (1992) destaca a importância de compreender as relações de gênero como relações de poder que ordenam os fenômenos socioculturais da existência humana. A dimensão 
do poder foi aprofundada no conceito elaborado por Joan Scott (1990), a qual evidencia a existência de uma conexão entre gênero e poder. Para a autora, o núcleo essencial do conceito de gênero está na relação entre duas proposições: "o gênero é um elemento constitutivo das relações sociais baseado nas diferenças percebidas entre os sexos, e o gênero é uma forma primeira de significar as relações de poder" (SCOTT, 1990, p. 14), isto é, o lugar primário no qual se articula o poder. O conceito de Scott ganhou importância nos estudos de gênero por inovar as concepções teóricas existentes até então, sobretudo, por introduzir a dimensão histórica, as relações de poder e a transversalidade de gênero como elemento cultural (FURLIN, 2014).

Llanos (2006) ressalta que a partir da definição de Scott a categoria de gênero ganhou o mesmo estatuto social da categoria de classe, etnia/raça, considerando que tais aspectos estão presentes em todas as relações sociais e se interseccionam mutuamente. E por ser um conceito que inclui a dimensão política, ao afirmar que o gênero é a forma primeira pela qual aprendemos as relações de poder.

O debate em torno do conceito de gênero, na década de 1990, recebe novos contornos teóricos ao incluir aspectos, como a posição de sujeito, a heteronormatividade, as identidades sexuais marginais e a corporalidade. Ganha importância a compreensão do corpo, não como uma estrutura fixa dada previamente pela natureza, sobre a qual se constrói culturalmente a distinção de gênero, mas como algo que é materializado pela cultura. Nessa perspectiva, a contribuição de Judith Butler (2003) concebe que tanto o gênero quanto o "sexo" são construídos pelos discursos culturais em contextos determinados. A autora desvela como o gênero é performaticamente produzido por práticas regularizadoras de coerência com o sistema da matriz heterossexual ${ }^{1}$. Assim, os gêneros "inteligíveis" ou aceitos socialmente são os que, de certa maneira, instituem e mantêm as relações de coerência e continuidade entre sexo, gênero, prática sexual e desejo (BUTLER, 2003, p. 38). Nessa lógica, certos tipos de “identidades” não podem "existir". Entretanto, Butler questiona a compreensão das identidades de gênero como resultado de uma coerência normativa entre sexo, gênero e desejo e mostra que a matriz cultural da inteligibilidade de gênero acaba excluindo outras possibilidades de "identidades".

O conceito de gênero, na interseção com outros marcadores sociais, legitimou-se como abordagem metodológica e analítica para a compreensão de como são produzidas as

\footnotetext{
${ }^{1}$ Butler usa o termo matriz heterossexual para significar a grade de inteligibilidade cultural por meio da qual os corpos, gêneros e desejos são naturalizados e conformados para serem aceitos dentro de determinada sociedade.
} 
desigualdades sociais. Também se constituiu uma importante ferramenta de luta política para mudar relações socioculturais desiguais, reduzir os processos de violência e discriminação social que atingem a diversidade das mulheres e a comunidade LGBT.

Nesse sentido, o presente artigo teórico-reflexivo evidencia como a perspectiva de gênero foi incorporada nas políticas educacionais, em vista de processos de transformação sociocultural e como ela se tornou um elemento de disputa política por parte dos setores conservadores, que distorcem significados, produzindo pânico moral ${ }^{2}$, de modo que "gênero" passou a ser um inimigo a ser combatido, ocultando, com isso, interesses que envolvem modelos de sociedade e de família.

Para tanto, dividimos este artigo em cinco blocos. Primeiro, pontuamos como o conceito de gênero foi incorporado na agenda política e, em seguida, discorremos sobre a importância da transversalidade de gênero nas políticas públicas. No terceiro bloco, evidenciamos a trajetória sobre gênero e sexualidades nas políticas educacionais, como estratégia de promoção de uma educação democrática e cidadã. No quarto ponto discutimos como a invenção da chamada "ideologia de gênero", por setores conservadores, tornou-se um dispositivo de poder e de ação política contra os avanços democráticos. Concluímos o artigo com uma reflexão sobre a relação entre gênero, direitos humanos e educação democrática, apontando como o discurso antigênero é uma ferramenta de violação dos direitos humanos e de contenção dos direitos das mulheres e das populações LGBT.

\section{Incorporação das políticas de gênero na agenda pública}

A incorporação das políticas de gênero na agenda pública foi resultado de diferentes fatores, como: compromissos jurídicos dos Estados e governos; pressão e mobilização das organizações de mulheres e de movimentos feministas em defesa dos direitos das mulheres, em um cenário social de violência doméstica, de discriminação e de desigualdades de gênero, que exigia uma resposta por parte das instituições estatais (SALAZAR, 2015).

O marco jurídico e político se consolidou a partir da década de 1990, por meio da realização de importantes convenções e conferências internacionais, nas quais foram criadas formas de apoio para a resolução dos problemas acerca das questões de gênero. E aqui fazemos menção à realização das várias Conferências Mundiais da ONU sobre os Direitos Humanos das

\footnotetext{
${ }^{2}$ Expressão usada por Miskolci e Campana (2017) em referência aos efeitos de uma retórica moral construída como possível ameaça para a sociedade.
} 
Mulheres $^{3}$ e da Convenção para Eliminação de Todas as Formas de Discriminação Contra a Mulher (CEDAW) de 1979, em vigor desde 1981, que foi o primeiro tratado internacional a abordar sobre os direitos humanos da mulher (BANDEIRA, 2004). Esses eventos, além das representações do Estado, contaram com o grande protagonismo e articulação transnacional dos movimentos feministas e de mulheres, fundamentais para definir pontos comuns de uma agenda política e para pressionar os governos nacionais a adotarem medidas políticas e jurídicas de promoção da igualdade de gênero e dos direitos das mulheres.

Os países signatários da Plataforma de Ação, que resultou da IV Conferência Mundial das Mulheres, realizada em Beijing em 1995, e da CEDAW ${ }^{4}$, comprometeram-se em assegurar os direitos das mulheres com a adoção de medidas legislativas, judiciais e administrativas, oferecendo relatórios sobre os avanços de sua aplicação. A Plataforma de ação apontou as 12 preocupações prioritárias para a ação dos $\operatorname{Estados}^{5}$, propondo aos Governos a criação de mecanismos estatais voltados à redução das desigualdades de gênero, em todas as dimensões sociais.

De acordo com Viotti (1995, p. 149.), a Plataforma de Ação se constituiu "um guia abrangente para orientar governos e sociedade no aperfeiçoamento do marco legal, na formulação de políticas e na implementação de programas para promover a igualdade de gênero e evitar a discriminação." Cabe destacar que a Plataforma de Ação de Pequim consagrou três inovações que apresentam potencial transformador na luta pela promoção da situação e dos direitos da mulher: o conceito de gênero, a noção de empoderamento e o enfoque da transversalidade.

Nesse sentido, a IV Conferência Mundial é considerada um marco histórico por duas razões: primeiro, por introduzir a perspectiva de gênero na explicação das desigualdades sociais entre mulheres e homens; segundo por impulsionar as políticas públicas para a igualdade, com a incorporação do enfoque de gênero. Assim, a Plataforma de Ação teve três importantes consequências: a) fortalecimento dos mecanismos nacionais para melhorar a vida das mulheres; b) o desenvolvimento das primeiras políticas públicas de igualdade; c) o impulso da transversalidade de gênero, como estratégia de política pública (SALAZAR, 2015).

\footnotetext{
${ }^{3}$ Conferências: do México em 1975; de Copenhague em 1980; de Nairóbi em 1990 e de Pequim em 1995.

${ }^{4}$ A CEDAW contempla as seguintes questões: a pobreza como violação aos direitos humanos; o direito à educação; o direito à participação da vida política, o direito de ter o acesso as mesmas oportunidades que os homens na esfera do trabalho, o direito da não discriminação na esfera da saúde, o direito de viver uma vida livre e sem violência (SALAZAR, 2015).

${ }^{5} \mathrm{E}$ uma dessas preocupações é sobre a desigualdade no acesso à educação e à capacitação. Para conhecer as outras 11 preocupações, consultar Viotti (1995).
} 
A Plataforma de Ação de Beijing se tornou um imperativo de ação para os governos, no sentido de integrar a perspectiva de gênero na legislação, nas políticas públicas, nos programas e projetos, com o compromisso de verificar, antes de sua implementação, os possíveis efeitos na vida das mulheres e homens (BANDEIRA, 2004).

A partir da década de 1999, os países criaram Mecanismos Institucionais em nível Nacional, como Conselhos, Secretarias ou Ministérios, com a função de promover a igualdade e a equidade de gênero por meio da articulação e implementação de políticas públicas com transversalidade de gênero, em todas as esferas políticas e níveis de atuação do governo, conforme as recomendações da Plataforma de Ação de Beijing. No Brasil, a criação da Secretaria Nacional de Políticas para as Mulheres, em 2003, no primeiro ano do governo Lula, foi o pontapé inicial para o fomento e implementação de políticas públicas com transversalidade de gênero, em todos os setores do governo, entre os quais, a educação.

\section{A transversalidade de gênero nas políticas públicas}

Lurdes Bandeira (2004) argumenta que as políticas de gênero não são políticas específicas para as mulheres, mas políticas que consideram os aspectos socioculturais que diferenciaram os processos de socialização para os homens e mulheres, que geraram consequências nas relações individuais e coletivas. São políticas que consideram "a natureza dos conflitos e das negociações que são produzidas nas relações entre homens e mulheres, bem como a dimensão da subjetividade que passa pela condição de sujeito.” (BANDEIRA, 2004, p. 9).

As políticas de gênero apresentam uma perspectiva relacional e permitem romper com padrões culturais tradicionais, em relação ao universo feminino. Assim, implementar políticas de gênero significa buscar mudanças sociais e culturais, ou seja, promover a condição emancipatória e a dimensão da autonomia das mulheres, criando os meios para a redução das desigualdades sociais de gênero (BRASIL, 2013). Em outras palavras, as políticas públicas de gênero visam garantir os direitos civis, políticos e sociais, ou os direitos humanos das mulheres e, no caso da educação, também das minorias sociais da comunidade LGBT. Sujeitos que foram privados ao longo da história, solidificando as desigualdades socioculturais entre mulheres e homens.

Segundo Stromquist (1996), as políticas de gênero devem levar à construção de uma democracia de gênero, um conceito que postula direitos iguais, chances iguais, acesso aos recursos econômicos e ao poder igual para homens e mulheres. Para a Comissão Econômica 
para a América Latina (CEPAL, 2017), as políticas públicas de gênero podem se definir como políticas orientadas para melhorar as condições de vida das mulheres e garantir seus direitos humanos. Trata-se de uma definição que se amplia, já que a mudança almejada, dependendo das políticas, abrange distintos níveis de profundidade. Contudo, elas sempre supõem reconhecimento social e político de que a situação das mulheres na sociedade precisa ser modificada e que o Estado deve assumir a tarefa de ativar os dispositivos disponíveis para que isso ocorra.

As políticas públicas de gênero partem da premissa de que as instituições estatais participam da construção política e social das relações de gênero e, por isso, devem estar comprometidas a combater a iniquidade e a desigualdade entre homens e mulheres. São políticas desenvolvidas em um contexto mais amplo, com o foco de promover a qualidade de vida para homens e mulheres, por meio do pleno exercício da cidadania. Tem como princípio o respeito às mulheres como sujeitos autônomos, ativos e participantes do desenvolvimento, social, político e econômico, buscando transcender os papéis sexuais que foram historicamente naturalizados pela cultura. Nessas políticas, as mulheres e também outras pessoas que não se identificam dentro do padrão heteronormativo da sociedade são consideradas não como sujeitos homogêneos, mas cidadão/as situados/as historicamente, membros da comunidade e portadoras de direitos (BANDEIRA; ALMEIDA, 2013).

A perspectiva transversal de gênero nas políticas educacionais somente começa a aparecer, de forma mais visível, a partir do início do século XXI, com a acessão dos governos do Partido dos Trabalhadores. Devido ao seu potencial de transformação cultural, tornou-se um campo de disputas políticas e resistência por parte dos setores conservadores da sociedade, como passaremos a abordar nos próximos pontos.

\section{Gênero e sexualidade nas políticas educacionais}

O tema da sexualidade no campo educacional não é um fato recente. De acordo com o estudo de Michel Foucault (1999), sobre a história da sexualidade, nas escolas do século XVIII, o saber sobre o sexo poderia ser encontrado nos dispositivos a arquitetônicos, regulamentos de disciplina e na própria estrutura organizativa do ensino. Esses dispositivos e estratégias, antes de se constituírem processos repressivos, produziram um discurso sobre a sexualidade no interior do campo educacional.

A partir do século XX, o discurso a respeito da sexualidade e, posteriormente, de gênero se tornam mais evidentes nas proposições de políticas públicas. De acordo com Claudia Vianna 
(2018), na década de 1920 houve a tentativa de incluir a educação sexual nas escolas públicas, por influência das correntes médicas higienistas da França. Depois desse período, não se evidenciou um debate mais intenso sobre a educação sexual. $\mathrm{O}$ tema voltou a ser abordado na década de 1960, após a realização do Vaticano II, nas escolas católicas e em algumas escolas públicas, cujo material, em geral, era escrito por padres, com base nas diretrizes cristãs, em uma perspectiva normativa. Nesse período, a sexualidade era um dispositivo de poder controlado pelo universo religioso.

Durante a ditadura militar tramitou no congresso uma proposta sobre a obrigação da educação sexual nas escolas públicas em todos os níveis, mas acabou sendo arquivada. A sexualidade no currículo ganhou certa visibilidade a partir da década de 1970, quando a Lei 5.692/71 colocou a educação sexual sob a reponsabilidade de orientadores educacionais e de docentes da área de Ciências ou de Programas de Saúde, com foco na perspectiva biológica e de saúde. Já na década de 1980, o tema da sexualidade é colocado em debate em espaços específicos, tratados por médicos e psicólogos, com o objetivo de prevenção de gravidez precoce e de doenças sexualmente transmissíveis e AIDS (VIANNA, 2018). Esse processo evidencia que o discurso da sexualidade na educação era um dispositivo de poder voltado para a produção de sujeitos autodisciplinados.

Segundo Vianna (2018), com a Constituição Federal de 1988 (CF/88), o Estado passa a assumir o protagonismo na educação para a sexualidade na educação básica, mas com foco na normatização dos comportamentos, segundo as convenções sociais. No entanto, na década de 1990, a pressão social dos movimentos feministas, diante das desigualdades entre homens e mulheres, deu ênfase ao debate sobre os direitos. O governo também foi pressionado a retomar a inclusão da sexualidade no currículo como resposta aos compromissos internacionais ${ }^{6}$, com a agenda de gênero e sexualidade como estratégia política para enfrentar as desigualdades socioculturais,

As Reformas Educacionais da década de 1990, no contexto da aprovação da Lei de Diretrizes de Bases em 1996, tiveram forte influência de Agências Multilaterais, como o Banco Mundial, Comissão Econômica para a América Latina (Cepal) e a Unesco. O objetivo dessa reforma foi "operacionalizar a regionalização no plano da cultura e das instituições, com foco da diversificação de conteúdos gerais e locais no currículo e na definição de competências a serem desenvolvidas.” (VIANNA, 2018, p. 74). Como parte dessa reforma, foram elaborados

\footnotetext{
${ }^{6}$ Esses compromissos resultaram das convenções e conferências mundiais da ONU, em que o Brasil foi signatário.
} 
os Parâmetros Curriculares Nacionais (PCN) ${ }^{7}$ os quais introduziram no ensino fundamental e médio o que se chamou de temas transversais, tendo como eixo central a educação para a cidadania $^{8}$. A sexualidade foi introduzida nos currículos das escolas por meio do tema orientação 9 sexual. Ao mesmo tempo que se constituiu um avanço foi também criticado por uma série de problemas de implementação, pela falta de formação inicial e continuada dos docentes e porque as temáticas de gênero e sexualidade ficaram subordinadas ao trinômio de corpo/saúde/doença (VIANNA; UNBEHAUM, 2006), ou por ser tratada em uma perspectiva informativa, como "fonte de prazer na vida", "necessidade básica", "potencialidade erótica do corpo" e "impulsos do desejo vividos no corpo" (ALTMANN, 2001). Para Helena Altmann, o fato de não se ter assumido uma abordagem sócio-histórica, não se avançou no processo de desconstrução dos preconceitos e tabus em torno das sexualidades.

Vianna (2018) avalia que na $\mathrm{CF} / 88$ e na $\mathrm{LDB}$ as questões de gênero não foram mencionadas de maneira explícita, mas permaneceram veladas em um discurso genérico e universal dos direitos humanos. Já no Plano Nacional de Educação (2001) e no PCN, as questões de gênero aparecem apenas em alguns tópicos, ora de forma reducionista, ora marcada por estereótipos, sabendo que nesse período o Brasil já era signatário de importantes tratados internacionais que exigiam das nações compromissos com a redução das desigualdades e discriminação de gênero.

Esse cenário mudou com a eleição do presidente Lula, que se mostrou mais favorável às políticas para a igualdade de gênero e manteve um diálogo produtivo com os movimentos feminista, negro, LGBT... A criação de mecanismos Institucionais, como a Secretaria Especial de Direitos Humanos (SEDH), a Secretaria Especial da Promoção da Igualdade Racial (SEPPIR), a Secretaria de Política para as Mulheres (SPM) e a forte participação dos movimentos e de organizações sociais na elaboração das políticas públicas, foram fatores favoráveis ao avanço da incorporação de gênero nas políticas educacionais e à elaboração de políticas com a interseccionalidade de raça, classe e gênero, sobretudo, na primeira década do século XXI.

Além das questões de gênero, a diversidade sexual passou a ser reconhecida no governo Lula, tendo um canal aberto de negociação e representação de atores políticos na estrutura do Estado, os quais foram membros de projetos e programas específicos. Isso fortaleceu a

\footnotetext{
${ }^{7}$ Os PCN visavam à flexibilização de conteúdos na estrutura curricular, oferecendo subsídio para municípios e estados elaborarem seus currículos a partir de suas realidades regionais.

${ }^{8}$ Esses temas transversais eram: ética, meio ambiente, pluralismo cultural, consumo, saúde e orientação sexual.

${ }^{9}$ No sentido de formação/instrução.
} 
construção de projetos anti-homofobia. Nesse sentido, a criação da Secretaria de Educação Continuada, Alfabetização e Diversidade (SECAD) ${ }^{10}$, vinculada ao MEC, foi um mecanismo importante que atuou em conjunto com a SEDH, articulando as ações de inclusão social com a valorização das diversidades na educação. Para Denise Carreira (2015), a SECAD teve um caráter inovador no MEC e nos demais ministérios, por se constituir como o lugar interseccional na organização e sustentação de agendas voltadas às diversidades na Educação. No que se refere aos temas de gênero e diversidade sexual, a SECAD buscava concretizar as ações do Plano Nacional de Políticas para as Mulheres e do Programa Brasil sem Homofobia, sobre educação inclusiva e não sexista, igualdade entre mulheres e homens e combate da discriminação de homossexuais.

Conforme Vianna (2018) e Carreira (2015), os principais avanços do Governo Lula foram as políticas voltadas para a Formação Docente, nas temáticas de gênero, sexualidades e combate à homofobia e ao sexismo, que ocorreram por meio de vários programas pontuais, como: Educação para a Diversidade e Cidadania (2005); Educando para Igualdade de Gênero, Raça e Orientação Sexual, realizado em cinco estados brasileiros, no ano de 2005; Formação de Profissionais da Educação para a Cidadania e a Diversidade Sexual, realizado nos anos de 2005 e 2006; Diversidade Sexual e Igualdade de Gênero nas Escolas em 2006 e 2007. O Programa de formação continuada de maior impacto, que se estendeu até o governo Dilma, foi o chamado Gênero e Diversidade na Escola (GDE), com início em 2006, realizado em parceria com SPM, SEPPIR e o Centro Latino Americano de Direitos Humanos (CLAM). Coordenado pela UFRJ e implantado, inicialmente, como projeto-piloto em seis municípios de diferentes estados do Brasil ${ }^{11}$. Em 2008, com a criação da Rede de Educação para a Diversidade, voltada à formação continuada de profissionais da educação, o GDE passou a ser oferecido por várias Universidades, por meio da Universidade Aberta Brasileira (UAB). Vianna (2018) menciona que vários trabalhos acadêmicos indicam a importância dessas políticas educacionais em gênero e diversidade sexual no fomento e elaboração de materiais educativos para projetos escolares e formação continuada docente.

Outro programa de grande impacto, que iniciou em 2005 e se estendeu até o golpe político, parlamentar e jurídico que destituiu Dilma da Presidência da República, foi sem dúvida o Programa Construindo a Igualdade de Gênero. Realizado com a parceria da SPM, CNPq e ONU Mulheres, teve como objetivo incentivar o debate e a produção de textos sobre gênero

\footnotetext{
${ }^{10}$ Responsável por articular programas de alfabetização, EJA, educação ambiental, indígena, do campo, combate à discriminação racial e sexual com projetos de valorização da diversidade étnica.

${ }^{11}$ Outros detalhes, consultar Vianna (2018).
} 
nos estabelecimentos de ensino públicos e privados, na rede de Educação Básica e o fomento da produção científica de estudantes da graduação e pós-graduação, no Ensino Superior.

Vale destacar que o Construindo a Igualdade de Gênero era parte do Programa Mulher e Ciência ${ }^{12}$, que visava promover a equidade de gênero na ciência, tendo três áreas de atuação: Edital Relações de Gênero, Mulheres e Feminismos; Prêmio Construindo Igualdade de Gênero; Encontro Nacional de Núcleos e Grupos de Pesquisa.

Em 2011, Dilma Rousseff assumiu a presidência da República como primeira mulher eleita pelo povo. Comprometeu-se a aprofundar as políticas de gênero iniciadas no governo Lula. Para a área da Educação a proposta era implementar políticas curriculares, em que a temática de gênero e diversidades sexuais se tornasse conteúdo obrigatório nas escolas. Contudo, com a ampliação da representação de grupos conservadores no Congresso Nacional, o seu governo foi marcado por conflitos e tensões em torno da agenda de gênero e diversidade sexual. Já no primeiro ano de governo, em 2011, por pressão da Frente Parlamentar Evangélica, Dilma vetou parte do material Didático do Kit Escola sem Homofobia, que seria distribuído nas escolas públicas para combater a discriminação e homofobia. Isso gerou insatisfação das forças políticas que apoiavam o governo Dilma.

A perspectiva de gênero nas políticas públicas, que visava criar processos de transformação cultural, foi sendo apropriada pelos grupos conservadores e difundida como "ideologia de gênero". Um termo carregado por significados distorcidos e politicamente nefastos, que gerou um pânico moral na opinião pública ${ }^{13}$. Isso ganhou notoriedade no processo de tramitação e aprovação do Plano Nacional de Educação (PNE) em 2013 e 2014, quando os grupos conservadores conseguiram articular uma "gramática política" (MISKOLCI; CAMPANA, 2017), que culminou na retirada dos termos gênero e orientação sexual do PNE Lei n. 13.005/2014 ${ }^{14}$. Travou-se uma disputa em torno de uma proposta educacional que deveria ser implantada na criação e aplicação de planos e programas elaborados no âmbito geral (VIANNA, 2018). Segundo Vianna, ao se aprovar como meta o combate das desigualdades educacionais, referida de forma genérica à erradicação de todas as formas de discriminação, estava-se assistindo à volta do caráter velado da menção de gênero nas políticas educacionais. Pode-se afirmar que essas tensões repercutiram posteriormente na elaboração da Base Nacional

\footnotetext{
12 Tinha como objetivos: incentivar as pesquisas científicas na área dos estudos de gênero; estimular a produção científica na graduação e pós-graduação na área de gênero e feminismos; aprofundar temas e projetos para a igualdade de gênero nas escolas de ensino médio e apoiar núcleos de estudos, agências de fomento, revistas com a temática dos Estudos de Gênero e Feminismos.

${ }^{13}$ Sobre essa questão aprofundaremos no ponto seguinte.

${ }^{14}$ Outros detalhes, ver Vianna et al. (2016).
} 
Curricular (BNCC), em que o gênero aparece de forma muito tímida, como evidencia o estudo de Constantina Xavier Filha (2019).

Apesar dessas tensões, o Governo Dilma aprovou as Diretrizes Nacionais para a Educação em Direitos Humanos (Parecer CNE/CP n. 8/2012), em que se faz referência a gênero e orientação sexual, ao enfatizar a necessidade de todas as pessoas usufruírem de uma educação não discriminatória e democrática, independentemente de sexo, orientação sexual, identidade de gênero, etc. (BRASIL, 2012). Também manteve a discussão em torno da deliberação n. 56, aprovada na Conferência Nacional de Educação (Conae) de 2014, que estabelecia a construção das Diretrizes Nacionais Curriculares sobre Educação, Gênero e Diversidade Sexual para a Educação Básica e Ensino Superior. Em meio aos retrocessos, isso foi possível em razão das alianças e esforços políticos de movimentos sociais de educação, LGBT e feministas. A construção dessas diretrizes visava institucionalizar e tornar efetiva uma política em educação e promover a equidade de gênero e de raça e o enfrentamento da homofobia. Contudo, com o golpe parlamentar, que destitui Dilma Rousseff da Presidência, o Conselho Nacional de Educação foi recomposto e esse processo foi paralisado (CARREIRA, 2016).

Um breve olhar sobre a trajetória de gênero e sexualidades nas políticas educacionais evidencia que algumas conquistas protagonizadas, sobretudo, no início do século XXI, foram resultado de intensa articulação política entre governos e movimentos sociais. É possível visualizar que as questões de gênero e diversidade sexual não encontraram um lugar consolidado nas políticas educacionais. A perspectiva de gênero, que havia sido tomada como importante ferramenta política para a transformação da cultura e para ampliar o debate sobre a qualidade da educação democrática que acolhe a todos, independentemente de sexo, cor, raça, atualmente se tornou alvo de disputa política de setores conservadores, sendo transformada em uma "ideologia" que ameaça as famílias e prejudica as subjetividades das crianças. Um discurso causador de pânico moral, reiterado no atual governo de Bolsonaro, incitando o ódio às diferenças e ocultando um projeto de ataque à educação democrática e aos direitos humanos, conforme discutiremos no próximo ponto.

\section{A invenção da "ideologia de gênero" como um dispositivo de poder e de ação política contra os avanços democráticos}

Os estudos de Junqueira (2017), Miguel (2016) e Miskolci e Campana (2017) apontam que a gênese do que se chamou "ideologia de gênero" emergiu no interior da ala conservadora da Igreja Católica. Uma "invenção" que surge junto ao Conselho Pontifício para a Família e em Conferências Episcopais, na década de 1990, com forte protagonismo de representantes da 
organização Opus Dei, cujo grupo exercia poder no papado de João Paulo II. O centro do debate desses grupos era alertar sobre os riscos da infiltração da perspectiva de gênero nas instituições, na política e na vida cotidiana. Segundo Junqueira (2017, p. 26), com esse discurso, o grupo conservador da Igreja Católica objetivava recuperar o espaço da Igreja na sociedade e "conter os avanços de políticas voltadas a garantir ou ampliar os direitos humanos das mulheres e de pessoas não-heterossexuais." É um discurso que defende a naturalização da diferença, de modelos de famílias e de sexualidades, fortalecendo as normas de gênero, a heterossexualidade obrigatória e a heteronormatividade das convenções sociais da cultura patriarcal.

De acordo com Miskolci e Campana (2017), as investidas contra gênero começam a aparecer nos Documentos do Vaticano a partir de 1997, sobretudo nos escritos do então Cardeal Josep Aloisius Ratzinger, como uma contraofensiva político-discursiva ao feminismo e à sua luta em favor do reconhecimento dos direitos sexuais e reprodutivos, bem como aos avanços protagonizados pela IV Conferência Mundial da Mulher da ONU, realizada em Pequim, no ano de 1995, cujo documento final adotou a perspectiva de gênero com conceito transversal para todas as políticas governamentais, em vista da superação das desigualdades de gênero e das discriminações sociais.

O uso do termo "ideologia de gênero", que hoje se tornou recorrente, apareceu pela primeira vez em um documento da Conferência Episcopal do Peru, em $1998^{15}$ e, posteriormente, em um documento da Cúria Romana, publicado em 2002, intitulado Família, Matrimônio e Uniões de fato. Em 2003, o Conselho Pontifício para a Família produziu um documento chamado Lexicon: termos ambíguos e discutidos sobre família, vida e questões éticas, que se constituiu uma espécie de dicionário com 103 verbetes, sobre temas relativos à sexualidade, gênero e bioética. Esse documento serviu de base para munir os bispos de argumentos para promover a "dignidade do matrimonio" e esclarecer a conduta a ser adotada pelos católicos frente às questões de gênero e sexualidade (JUNQUEIRA, 2017) ${ }^{16}$. Segundo Junqueira, os artigos do Lexicon reverberam discursos sexistas e homofóbicos promovidos por grupos pró-vida e comunidades terapêuticas de cura gay. Também se encontram filosoficamente atrelados à doutrina professada pela Opus Dei e à teologia do corpo, formulada por Karol Wojtyla.

\footnotetext{
${ }^{15}$ Intitulado La ideología de género: sus peligros y alcances, elaborada pelo Bispo Auxiliar de Lima, Oscar Alzamora, da ala conservadora da Igreja, baseado no artigo O'Leary (1995), redigido para subsidiar os trabalhos preparatórios dos grupos pró-vida e pró-família para a Conferência de Pequim. Esse documento e mais o artigo Qué quiere decir género? Em torno a um nuevo modo de hablar, escrito em 2001, pela teóloga alemã da Opus Dei, Jutta Burggraf, foram textos de iniciação para quem quisesse aprender sobre a "ideologia de gênero" para combatê-la (JUNQUEIRA, 2017).

${ }^{16}$ Detalhes sobre essas publicações e documentos, consultar Junqueira (2017).
} 
O Lexicon defende a "família natural”, constituída de pai, mãe e filhos, como único modelo e a educação sexual como primado da família, sublinhando os limites da educação sexual no âmbito escolar. Construiu um discurso contra os avanços das conferências da ONU, em relação às políticas que ampliam os direitos sexuais das mulheres e das comunidades LGBTs (JUNQUEIRA, 2017).

$\mathrm{Na}$ América Latina, a batalha contra a "ideologia de gênero" se tornou mais conhecida a partir do Documento de Aparecida, que resultou das discussões da V Conferência Geral do Episcopado Latino-americano e Caribe, em 2007. Nesse documento, a "ideologia de gênero" aparece como responsável pelo enfraquecimento da "família", por preconizar que cada um pode escolher a sua orientação sexual, sem observar as diferenças da natureza humana. Há uma distorção do conceito de gênero e uma defesa do conceito tradicional de família. Essas ideias ganharam força e se espalharam com a publicação do livro La ideologia del género. O el género como herramienta de poder ${ }^{17}$, em 2010, do argentino Jorge Scala, um advogado católico do grupo pró-vida. $\mathrm{O}$ autor faz uma interpretação distorcida de gênero, cujo sentido posteriormente é incorporado no discurso político. Segundo ele, "a perspectiva de gênero é, na verdade, uma ideologia e, provavelmente a mais radical da história, posto que ao impor-se, destruiria o ser humano em seu núcleo mais íntimo e, simultaneamente, acabaria com a sociedade." (SCALA, 2010, p. 7). Para Scala, a “ideologia de gênero” é um instrumento político-discursivo com um alcance de manipulação global, que estabelece um modelo totalitário, cuja finalidade é a imposição de uma nova antropologia que visa alterar as pautas morais e destruir a sociedade (MISKOLCI; CAMPANA, 2017). As suas ideias reforçam os argumentos dos documentos do Vaticano em defesa da família tradicional, como núcleo da vida em sociedade, fazendo oposição aos avanços democráticos, em relação aos direitos sexuais e reprodutivos.

Na visão de Scala esses direitos são resultados da manipulação da linguagem, em que os "ideólogos de gênero" procuram convencer seus interlocutores com argumentos de que se trata de direitos humanos e, assim, "impõem" sem resistência o que apresentam como resultado de um consenso democrático e, por isso, visto como algo bom, mesmo quando é um ato criminoso, já que ninguém poderia se opor à defesa dos direitos humanos (MISKOLCI; CAMPANA, 2017). O pensamento de Scala evidencia como para os conservadores a promoção de certos direitos humanos é compreendida como ameaça à família "natural”. Com a oposição aos avanços democráticos protagonizados, em grande parte, pelo feminismo e pela população LGBT, segundo Miguel (2016), a Igreja pretende manter sua autoridade e influência em um

\footnotetext{
${ }^{17}$ Traduzido para o português, em 2011, com o título Ideologia de Gênero: neototalitarismo e a morte da família.
} 
contexto de secularização. Isto é, ela "reforça a sua centralidade política na medida em que busca despolitizar determinadas questões, invocando-as para a esfera em que a sua autoridade seria mais legitima, que é a esfera da moral.” (MIGUEL, 2016, p. 597).

A doutrina católica contra o gênero iniciou no pontificado de João Paulo II e se fortaleceu no de Bento XVI. Nesse período, os documentos eclesiais destacam a importância do papel social das mulheres, desde uma perspectiva essencialista. $\mathrm{O}$ discurso católico que, ao longo da história da Igreja, apresentava certa aversão às mulheres, passa a exaltar os seus papeis tradicionais ${ }^{18}$. No cenário de exaltação do feminino, "a igualdade pretendida pelo feminismo representaria um rebaixamento da mulher, a perda de sua 'dignidade extraordinária' na condição de 'especialista do amor'." (MIGUEL, 2016, p. 598). Essas ideias essencialistas, fundadas em uma suposta natureza biológica, tornam-se base para os argumentos dos pensadores católicos contra a perspectiva de gênero nas políticas públicas, visto que essa categoria apresentava um potencial de transformação cultural, que desestabilizaria as crenças baseadas em uma natureza fixa do feminino e do masculino.

De acordo com Junqueira (2017), o sintagma "teoria de gênero" ou "ideologia de gênero" se desloca do contexto dos discursos do vaticano e passa a animar as ações midiáticas e, aos poucos, legitima-se como categoria política, delineando documentos estatais e discursos de dirigentes políticos, com aparência de laicidade. Nesse sentido, vale reforçar os argumentos de Miskolci e Campana (2017, p. 729).

\begin{abstract}
A partir de diversas ações políticas (como lobby legislativo ou denúncias a funcionários públicos), jurídicas (como a apresentação de ações judiciais em que usam argumentos legais e "científicos" sobre os perigos da "ideologia de gênero" para a sociedade) e midiáticas (através de manifestações públicas, programas de rádio e televisão ou congressos "acadêmicos") instalam nas discussões públicas os "perigos sociais" que representariam essa "ideologia". Essas organizações se apresentam como seculares e democráticas, genuínas representantes da sociedade civil, e, portanto, interlocutoras legítimas na hora de estabelecer negociações com os poderes do Estado.
\end{abstract}

Miskolci e Campana apontam que a cruzada contra a "ideologia de gênero", na arena política, não é liderada somente por atores conservadores das instituições católicas, mas agrega também organizações evangélicas neopentecostais e, no caso do Brasil, atores conservadores do Programa Escola sem Partido. Essa organização não somente se mobiliza contra o que

\footnotetext{
${ }^{18}$ É preciso ressaltar que esse destaque ao papel das mulheres na igreja e na sociedade, no discurso eclesial, embora em uma perspectiva tradicional, tem sido influenciado pelos direitos e espaços de visibilidade que as mulheres foram conquistando no cenário público, a partir da década de 1970. Com isso, parecia interessante que a Igreja visibilizasse e exaltasse os papéis femininos, desde que as mulheres permanecessem em um lugar subalterno, em termos de poder.
} 
chamam de "doutrinação política e ideológica", mas busca criminalizar todas as iniciativas educacionais propostas "que abordem temas como: desigualdades de gênero, diversidade sexual (na escola e na sociedade), combate ao preconceito, ao sexismo e à LGBTfobia." (CIAVATTA, 2017, p. 13).

O discurso da "ideologia de gênero" se constituiu uma ferramenta de luta contra as políticas sociais, reformas jurídicas e ações pedagógicas voltadas a promover os direitos sexuais, a enfrentar preconceitos, a prevenir violências e a combater discriminações (hetero)sexistas. Observa-se que os grupos conservadores se apropriaram do conceito de gênero que nos estudos acadêmicos é compreendido como uma categoria analítica que possibilita compreender e desnaturalizar relações sociais e processos históricos de produção das desigualdades de gênero e o transformam em um projeto reacionário, baseado em sentidos distorcidos. Assim, a retórica "ideologia de gênero" constituiu-se um dispositivo de poder reacionário usado para intimidar, ameaçar pesquisadores/as, atores/atrizes sociais e instituições comprometidas com a implementação de políticas sociais ou pedagógicas que se opõem aos interesses dos que se afirmam defensores da família, dos valores morais e religiosos as tradicionais.

A noção ideologia de gênero se tornou articuladora de um campo discursivo de ação, no sentido de Miskolci e Campana (2017), que não apenas produziu um pânico moral na opinião pública, mas também agregou forças políticas contra os avanços democráticos nas políticas educacionais. Nesse cenário, como já pontuamos, no Brasil temos as polêmicas em torno do Kit Escola sem Homofobia em 2011, que gerou o veto da presidenta Dilma Rousseff de parte do material pedagógico e o forte embate em torno das proposições para promover a igualdade de gênero e o respeito às diversidades sexuais, na formulação do PNE, aprovado em 2014 e, posteriormente, em torno dos Planos Municipais e Estaduais de Educação. As propostas educacionais inclusivas que objetivavam combater a discriminação, valorizar o pluralismo, a laicidade, o reconhecimento das diferenças e garantir uma formação cidadã passaram a ser denunciadas como ameaça à liberdade de expressão e aos valores morais e religiosos. Em torno dessa disputa o movimento antigênero foi se fortalecendo, atacando currículos escolares, a liberdade docente e defendendo a primazia da família na educação moral dos filhos. Esse "movimento" articulou grupos conservadores, sobretudo lideranças da Frente Parlamentar Evangélica, do Movimento Escola sem Partido e do catolicismo de perspectiva neopentecostal.

Tais retrocessos nas políticas educacionais são efeitos da reiteração de uma falsa conotação do que se denominou "ideologia de gênero", "denunciada como "doutrinação neototalitária', de raiz marxista e ateia e ainda mais perigosa do que o marxismo, camuflada em 
discursos sobre emancipação, liberdade e igualdade." (JUNQUEIRA, 2017, p. 30). O gênero se tornou um inimigo a ser combatido porque queria promover a destruição da família "tradicional", confundir a identidade de gênero das crianças e adolescentes, legalizar a pedofilia e decretar o fim da “ordem natural”. Para Reis e Eggert (2017), trata-se de uma visão que nega os dados oficiais e estudos científicos sobre a existência das desigualdades de gênero, a discriminação e a violência contra as mulheres e pessoas LGBT.

Se formulou argumentos sem fundamentos científicos e replicando-os nas mídias sociais para serem engolidos e regurgitados pelos fiéis acríticos que os aceitam como verdades inquestionáveis. Utilizou-se também de uma espécie e terrorismo moral, atribuindo o status de demônio às pessoas favoráveis ao respeito à igualdade de gênero e diversidade sexual na educação, além de intimidar profissionais de educação com notificações extrajudiciais com ameaça de processo contra quem ousasse abordar esses assuntos na sala de aula. (REIS; EGGERT, 2017, p. 21).

A produção desse pânico moral, em torno da chamada "ideologia de gênero", constituiuse uma estratégia político-reacionária para conter os avanços democráticos e suprimir as temáticas de gênero e diversidade sexual do currículo escolar. Isso reforça o argumento de que um currículo nunca é neutro, mas construído em sintonia com os fenômenos sociais e culturais de determinada época, como bem nos lembra Michael W. Apple (2018, p. 59):

O currículo nunca é apenas um conjunto neutro de conhecimentos [...] Ele é sempre parte de uma tradição seletiva, resultado da seleção de alguém, da visão de algum grupo acerca do que seja conhecimento legítimo. É produto de tensões, conflitos e concessões culturais, políticas e econômicas que organizam e desorganizam um povo.

E em se tratando dos conteúdos de gênero e de diversidade sexual, em um contexto de emergência de forças políticas conservadoras, o que parece estar em jogo é a necessidade de se conter os processos de mudanças culturais, impedindo a implementação de políticas educacionais que promovam a igualdade de gênero e o avanço dos direitos sexuais e reprodutivos. Assim, nesse cenário, o conhecimento válido parece ser o que reproduz os valores da família tradicional, da heterossexualidade compulsória e da heteronormatividade nas relações sociais.

É possível constatar que os sentidos produzidos para a chamada "teoria/ideologia de gênero" não equivalem aos produzidos pelos estudos de gênero, como relacionamos no início deste trabalho ${ }^{19}$. Trata-se de uma invenção do catolicismo conservador, que penetra o campo

\footnotetext{
${ }^{19}$ Vale ressaltar que nos estudos acadêmicos não existe uma teoria de gênero, mas várias teorias que contemplam
} as diferentes perspectivas disciplinares e as várias matizes teóricas e políticas. Assim, gênero é compreendido 
da ação estatal, funcionando como uma arma política e um discurso reacionário de ataque às políticas por igualdade de gênero e não discriminação. É compreendido pela literatura científica como um discurso heterossexista, antifeminista e de desqualificação aos estudos de gênero. Segundo Junqueira (2017), trata-se de um dispositivo de poder que opera para conter ou anular o potencial crítico e emancipador do feminismo e dos estudos de gênero, desqualificando seus fundamentos e atores, para fortalecer o poder dos valores morais e religiosos dos setores tradicionalistas e ultraconservadores, como os únicos legítimos para a sociedade.

\section{Considerações finais: Educação Democrática ou de contenção de direitos}

A ONU considera que a Educação é um dos pilares fundamentais dos direitos humanos, da democracia, do desenvolvimento sustentável e da paz. Na mesma direção, Norbert Bobbio afirma que é mediante o nexo entre paz e os direitos humanos que se instauram os princípios da governança democrática. Isto é, direitos humanos, democracia e paz são três momentos necessários do mesmo movimento histórico, pois "sem direitos humanos reconhecidos e protegidos, não há democracia e sem democracia, não existem condições mínimas para a solução pacífica dos conflitos sociais.” (BOBBIO, 2004, p. 1). A pluralidade e a diversidade nas diversas dimensões da vida são princípios da democracia e seguem na contramão dos mecanismos que impõem, sobre o conjunto da sociedade, uma única visão de mundo, com seus dogmas e crenças, inclusive, no âmbito das relações de gênero e sexualidade.

Nessa compreensão, os esforços dos governos, durante o processo e redemocratização, sobretudo na primeira década do século XXI, em criar mecanismos específicos nas estruturas estatais, para implementar políticas educacionais com enfoque de gênero e sexualidades, fortaleceram o papel da educação na promoção dos direitos humanos e da convivência democrática e pacífica. Vale ressaltar, que a partir do século XXI se consolidou o entendimento que não somente a equidade de gênero, mas também a identidade de gênero e a liberdade de viver a própria orientação sexual compõem o conjunto dos direitos humanos ${ }^{20}$. Nesse sentido, no que diz respeito à educação, os Princípios de Yogyakarta sobre a Aplicação da Legislação

como um conceito analítico, com o mesmo status social do conceito de classe e raça e não uma "teoria" ou uma "ideologia", como foi construída pelo catolicismo conservador. Desde a perspectiva dos estudos sociológicos, o termo ideologia de gênero se remete às posições radicalizadas, ou seja, justamente o que os seus idealizadores pregam, isto é, o sexismo, a homofobia e, a transfobia, a intolerância em relação às diferenças.

${ }^{20}$ Reis e Eggert (2017, p. 12) apontam que tanto a "Organização das Nações Unidas (ONU) quanto a

Organização dos Estados Americanos (OEA) aprovaram declarações e resoluções afirmando que a orientação

sexual e a identidade de gênero também devem ser consideradas como direitos humanos." 
Internacional de Direitos Humanos em Relação à Orientação sexual e Identidade de Gênero (2007), afirmam "que toda a pessoa têm direito à educação, sem discriminação por motivo de sua orientação sexual e identidade de gênero, e ser respeitado nessas características." (PRINCÍPIOS DE YOGYAKARTA, 2007, p. 23). O documento também enuncia que é dever dos Estados criar medidas para acesso igual à educação, tratamento igualitário e respeito aos direitos humanos, protegendo esses indivíduos dos processos de exclusão, violência e discriminação (PRINCÍPIOS DE YOGYAKARTA, 2007).

A perspectiva de gênero nas políticas e no currículo educacional não apenas é uma estratégia para construir uma sociedade igualitária, que promove e respeita os direitos humanos, como permite ampliar a qualidade da educação como espaço democrático que acolhe, inclui e respeita todas as pessoas, independentemente de sexo, raça e classe social. Por isso, ao contrário de confundir a identidade das crianças e dos jovens ou de destruir as famílias, como afirmam os "empreendedores da moral tradicional" (MILKOSCI; CAMPANA, 2017), a perspectiva de gênero na educação ensina a acolher e a respeitar todas as formas de ser masculino e feminino e todas as formas de organização familiar. Pode-se dizer que há uma relação direta entre gênero, direitos humanos e educação democrática.

Ao atacar gênero, por meio de uma leitura distorcida e superficial dessa categoria, os setores conservadores não somente menosprezam e desqualificam o seu caráter científico, como transformam o que chamam de "ideologia de gênero", em uma arma político-reacionária para reproduzir ou reinstaurar padrões ou valores tradicionais, que alimentam processos de exclusão, discriminação, desinformação e de violação dos direitos humanos. Isto é, trata-se de uma ação discursiva que exclui e discrimina indivíduos e grupos, cujas condutas são dissonantes da norma heterossexual da cultura patriarcal, afetando não apenas os direitos individuais, como, também, compromete os direitos sociais de acesso à educação, ao trabalho e aos espaços de lazer. O discurso antigênero na educação não promove uma conduta "moral" e valores cristãos como os seus adeptos afirmam, ao contrário, alimenta processos de preconceito, ódio, ameaçando, inclusive, o direito à vida das minorias sociais, que carregam em seus corpos marcas de gênero consideradas não inteligíveis ou "anormais", segundo os padrões normativos da heterossexualidade obrigatória (BUTLER, 2003).

Esse ensaio reflexivo nos permite afirmar que a ação político-reacionária de silenciar a escola com a retirada dos temas de gênero e sexualidade viola o direito a uma educação de qualidade para a cidadania e para a democracia plural. É, antes de tudo, uma tentativa de conter o avanço dos direitos das mulheres e da população LGBT para fortalecer os valores heteronormativos da cultura patriarcal. 
Em um contexto de política neoliberal combinada com o neoconservadorismo, fazer a memória da trajetória das políticas de gênero e clarear o sentido do conceito de gênero, enquanto categoria científica, constitui-se uma estratégica de resistência diante da ação discursiva nomeada como "ideologia de gênero", que tem se fortalecido no atual governo, cuja intenção oculta interesses políticos voltados a enfraquecer um projeto de sociedade pautado na igualdade de gênero e em valores democráticos. Assim, nesse contexto, a posição antigênero dos fomentadores do pânico moral, não é uma questão epistemológica ou teórica, mas política, de modo que gênero se transformou em um campo de disputa política, que coloca em jogo um modelo de sociedade pautada na democracia e na igualdade de direitos.

O campo das políticas educacionais é hoje um lugar de disputa. Os grupos conservadores se apropriam das ideias progressistas e as transformam em um projeto reacionário. Como educadores/as e cientistas sociais temos como desafio atual transmitir o conhecimento científico e provocar nos estudantes a argumentação das ideias. Segundo Boaventura Santos, na conferência de abertura da $39^{\mathrm{a}}$ Reunião da ANPED de $2019^{21}$, nós não podemos ser cúmplices das ideias conservadoras, pois se não fizermos nada para desmascarar e nos opor à chamada "ideologia de gênero", seremos cúmplices com a violência contra as mulheres, com as desigualdades e com todas as formas de discriminação de gênero. Em outras palavras, seremos cúmplices da contenção e da violação dos direitos humanos. E não haverá democracia se não houver direitos respeitados e garantidos.

\section{REFERÊNCIAS}

ALTMANN, Helena. Orientação sexual nos Parâmetros Curriculares Nacionais. Estudos Feministas, Rio de Janeiro, v. 9, n. 2, p. 575, 2001.

APPLE, Michael W. A política do conhecimento oficial: faz sentido a ideia de um currículo nacional. In: MOREIRA, Antonio Flávio; TADEU, Tomaz. Currículo, Cultura e Sociedade. São Paulo: Editora Cortez, 2018.

BANDEIRA, Lourdes M.; ALMEIDA. Tânia M. Campos de A transversalidade de gênero, nas políticas públicas. Revista do Ceam, v. 2, n. 1, jan./jun. 2013.

BANDEIRA, Lourdes M. A transversalidade da perspectiva de gênero nas políticas públicas. Brasília, DF: CEPAL/SPM, 2004.

BEAUVOIR, Simone. O segundo sexo: fatos e mitos. São Paulo: Círculo do Livro, 1949. v. 1 .

\footnotetext{
${ }^{21}$ Confere vídeo da conferência da abertura da ANPED, 2019. Disponível em:
} https://www.youtube.com/watch?v=P4D75GOSMXg\&feature=emb_logo 
BOBBIO, Norberto. A era dos direitos. Rio de Janeiro: Elsevier, 2004.

BRASIL. Políticas Públicas para as Mulheres. Brasília, DF: SPM, 2013. Cartilha.

BRASIL. Conselho Nacional de Educação. Parecer n. 8, de 6 de março de 2012. Aprova as Diretrizes Nacionais para a Educação em Direitos Humanos. Diário Oficial da República Federativa do Brasil, Brasília, DF, 30 maio 2012a. Disponível em: http://portal.mec.gov.br/index.php?option=com_docman\&view=download\&alias=10389-pcp 008-12-pdf\&category_slug=marco-2012-pdf\&Itemid=30192. Acesso em: 10 jun. 2020.

BUTLER, Judith. Problemas de gênero: feminismo e subversão da identidade. Rio de Janeiro: Civilização Brasileira, 2003.

CARREIRA, Denise. Igualdade e diferenças nas políticas educacionais: a agenda das diversidades nos governos Lula e Dilma. 2015.508 p. Tese (Doutorado em Educação) Universidade de São Paulo, São Paulo, 2015.

CARREIRA, Denise. O Informe Brasil Gênero e Educação: Da CONAE às Diretrizes Nacionais. In: VIANNA, Cláudia et al. Gênero e educação: fortalecendo uma agenda para as políticas educacionais. São Paulo: Ação Educativa, Cladem, Ecos, Geledés, Fundação Carlos Chagas, 2016. p. 25-54.

CEPAL. Planes de igualdad de género en América Latina y el Caribe: Mapas de ruta para el desarrollo. Observatorio de Igualdad de Género de América Latina y el Caribe. Estudios 1, Naciones Unidas, Santiago: LC/PUB. 1-P, 2017.

CIAVATTA, Maria. Resistindo aos dogmas do autoritarismo. In: FRIGOTTO, Gaudêncio (org.). A gênese das teses do Escola sem Partido: esfinge e ovo da serpente que ameaçam a sociedade e a educação. Rio de Janeiro: UERJ, LPP, 2017. p. 7-16.

FILHA, Constantina Xavier. Gênero e Direitos Humanos na Base Nacional Comum Curricular. In: SILVA, Fabiany de Cassia T.; FILHA, Constantina Xavier (org.).

Conhecimentos em disputa na Base Nacional Comum Curricular. Campo Grande: Editora Oeste, 2019.

FLAX, Jane. Pós-modernismo e as relações de gênero na Teoria Feminista. In: HOLLANDA, H. (org.). Pós-modernismo e política. Rio de Janeiro: Rocco, 1992. p. 217-250.

FOUCAULT, Michel. História da sexualidade: a vontade de saber. 13. ed. São Paulo: Edições Graal, 1999.

FURLIN, Neiva. Relações de gênero, subjetividades e docência feminina: um estudo a partir do universo do ensino superior em teologia católica. 2014. 386 p. Tese (Doutorado em Sociologia) - Programa de Pós-graduação em Sociologia da Universidade Federal do Paraná, Curitiba, 2014.

JUNQUEIRA, Rogério Diniz. "Ideologia de gênero": a gênese de uma categoria política reacionária - ou: a promoção dos direitos humanos se tornou uma "ameaça à família natural". In: RIBEIRO, Paula Regina Costa; CORPES, Joanalira (org. CARREIRA, Denise. Igualdade e diferenças nas políticas educacionais: a agenda das diversidades nos governos Lula e 
Dilma. São Paulo: USP, 2015. Tese (Doutorado em Educação) - Universidade de São Paulo, São Paulo, 2015.

LLANOS, Gabriela Castellano. Sexo, género y feminismos: tres categorías en Pugna. Cali, Colombia: Universidad del Vale, 2006.

LOURO, Guacira L. Gênero, sexualidade e educação. 3. ed. Petrópolis: Editora Vozes, 1999.

MIGUEL, Luis Felipe. Da "doutrinação marxista" à "ideologia de gênero": Escola sem Partido e as leis da mordaça no parlamento brasileiro. Direito \& Práxis, Rio de Janeiro, v. 7, n. 15, p. 590-621, 2016.

MISKOLCI, Richard; CAMPANA, Maximiliano "Ideologia de gênero": notas para a genealogia de um pânico moral contemporâneo. Revista Sociedade e Estado, v. 32, n. 3, p. 725-747, set./dez. 2017.

PRINCÍPIOS DE YOGYAKARTA. Princípios sobre a aplicação da legislação internacional de direitos humanos em relação à orientação sexual e identidade de gênero. 2007. Disponível em: http://

www.dhnet.org.br/direitos/sos/gays/principios_de_yogyakarta.pdf. Acesso em: 12 jul. 2020.

REIS, Toni; EGGERT, Edla. Ideologia de gênero: uma falácia construída sobre os planos de educação brasileiros. Educação e Sociedade, Campinas, v. 38, n. 138, p. 9-26, jan./mar. 2017.

RUBIN, Gayle. O tráfico de mulheres: notas sobre a "economia política" do sexo. Pernambuco: SOS Corpo, 1993.

SALAZAR, Ana L. Flores. Políticas públicas de igualdad de género en Chile y Costa

Rica: Um estúdio comparado. Tese (Doctorado en Gobierno y Administración Pública), 358p, Universidad Complutense de Madrid, Instituto Universitario de Investigación Ortega y Gasset, 2015.

SCALA, Jorge. La ideología del género. O el género como herramienta de poder. Rosario: Ediciones Logos, 2010.

SCOTT, Joan W. Gênero: uma categoria útil de análise histórica. Revista Educação e Realidade, Porto Alegre: UFRGS, v. 16, n. 2, p. 5-22, 1990.

STROMQUIST, Nelly P. Políticas públicas de Estado e equidade de gênero: Perspectivas comparativas. Revista Brasileira de Educação, n. 1, p. 27-49, jan./abr. 1996.

VIANNA, Cláudia; UNBEHAUM, Sandra. Gênero na educação básica: quem se importa? Uma análise de documentos de políticas públicas no Brasil. Educação e Sociedade, Campinas, v. 27, n. 95, p. 407-428, maio/ago. 2006.

VIANNA, Claudia. Políticas de Educação, gênero e diversidade sexual: breve história de lutas, danos e resistências. Belo Horizonte: Autêntica Editora, 2018. (Série Cadernos da Diversidade). 
VIANNA, Cláudia et al. Gênero e educação: fortalecendo uma agenda para as políticas educacionais. São Paulo: Ação Educativa, Cladem, Ecos, Geledés, Fundação Carlos Chagas, 2016.

VIOTTI, Maria Luiza Ribeiro. Declaração e Plataforma de Ação da IV Conferência Mundial Sobre a Mulher. Pequim, 1995. Instrumentos internacionais de direitos das mulheres, p. 148-158, 1995. Disponível em:

http://www.unfpa.org.br/Arquivos/declaracao_beijing.pdf. Acesso em: 17 maio 2020.

\section{$\underline{\text { SOBRE A AUTORA }}$}

\section{Neiva Furlin}

Doutora em Sociologia pela Universidade Federal do Paraná (UFPR), com doutorado sanduíche na Universidade Nacional Autónoma de México (UNAM). Pós-doutorado em Ciências Sociais pela Universidade Estadual de Maringá (UEM). Atualmente é professora permanente do Programa de Pós-Graduação em Educação da Universidade do Oeste de Santa Catarina (UNOESC), pesquisadora do Núcleo de Estudos e Pesquisas em Políticas Educacionais (NUPE) e líder do Grupo de Pesquisa Educação, Políticas Públicas e Cidadania (GEPPeC).

E-mail: nfurlin@yahoo.com.br

(iD https://orcid.org/0000-0002-5103-2104 